\title{
Effect of nanoscale 2precipitation on strain localisation in a two-phase Ti-alloy
}

DOI:

10.1016/j.actamat.2017.02.068

\section{Document Version}

Accepted author manuscript

Link to publication record in Manchester Research Explorer

\section{Citation for published version (APA):}

Lunt, D., Busolo, T., Xu, X., Quinta da Fonseca, J., \& Preuss, M. (2017). Effect of nanoscale 2precipitation on strain localisation in a two-phase Ti-alloy. Acta Materialia, 129, 72-82.

https://doi.org/10.1016/j.actamat.2017.02.068

\section{Published in:}

Acta Materialia

\section{Citing this paper}

Please note that where the full-text provided on Manchester Research Explorer is the Author Accepted Manuscript or Proof version this may differ from the final Published version. If citing, it is advised that you check and use the publisher's definitive version.

\section{General rights}

Copyright and moral rights for the publications made accessible in the Research Explorer are retained by the authors and/or other copyright owners and it is a condition of accessing publications that users recognise and abide by the legal requirements associated with these rights.

\section{Takedown policy}

If you believe that this document breaches copyright please refer to the University of Manchester's Takedown Procedures [http://man.ac.uk/04Y6Bo] or contact uml.scholarlycommunications@manchester.ac.uk providing relevant details, so we can investigate your claim.

\section{OPEN ACCESS}




\title{
Effect of nanoscale $\alpha_{2}$ precipitation on strain localisation in a two-phase Ti-alloy
}

D. Lunt ${ }^{1}$, T. Busolo ${ }^{1}, X . \mathrm{Xu}^{1}$, J. Quinta da Fonseca ${ }^{1}$, M. Preuss ${ }^{1}$

${ }^{1}$ Material Science Centre, University of Manchester, Manchester, M13 9PL, UK

\begin{abstract}
Many commercial Ti-alloys contain $6 \mathrm{wt} . \%$ Aluminium and these alloys are prone to precipitation of $\alpha_{2}\left(\mathrm{Ti}_{3} \mathrm{Al}\right)$. Here, we investigate and quantify the effect of $\alpha_{2}$ precipitation on strain localisation behaviour for Ti-6Al-4V with an equiaxed microstructure using High Resolution Digital Image Correlation (HR-DIC) in combination with Electron Back Scatter Diffraction (EBSD). HR-DIC has enabled us to quantify strain localisation, which shows that at $1 \%$ applied strain the strain heterogeneity in terms of maximum shear strain is about twice in the sample containing $\alpha_{2}$ precipitates compared to the $\alpha_{2}$-free sample. Theoretical slip trace angles for all possible slip systems were calculated using Electron Back Scatter Diffraction (EBSD) orientation data and cross-correlated with experimental slip trace angles measured from nanoscale shear strain maps recorded by HRDIC to predict the active slip domain. It has been found that while slip type activity in terms of frequency is strongly dependent on texture in respect to loading direction, the actual shear strain contribution from prismatic slip does increase significantly in the presence of $\alpha_{2}$ precipitation. This experimental observation supports previous calculations of Anti-Phase Boundary (APB) energies for $\alpha_{2}$ precipitates [1] where widely dissociated partial dislocations on the prismatic plane show a lower APB energy than the APB energy associated with shearing on the basal plane in $\alpha_{2}$.
\end{abstract}

Keywords

Titanium alloys, HR-DIC, Tensile, EBSD, Strain Heterogeneity, $\alpha_{2}$ precipitates

\section{Introduction}

Titanium alloys continue to be a crucial material for the aerospace manufacturers in the effort to improve fuel efficiency and performance of aircraft [2] due to their high specific strength and corrosion resistance [3]. The workhorse titanium alloy for aerospace applications is the $\alpha+\beta$ alloy Ti-6Al-4V, due to favourable mechanical performance including fatigue properties at moderate temperatures and relatively good manufacturability compared to more advanced Ti-alloys [4]. The mechanical properties of this alloy can be tailored by modifying the two-phase microstructure through thermomechanical processing. An essential part of the thermomechanical process is the annealing stage, as it can relieve internal stresses and age harden the alloy [4]. In Ti-6Al-4V, age hardening can be achieved by the formation of ordered and coherent $\alpha_{2}$ precipitates $\left(\mathrm{Ti}_{3} \mathrm{Al}\right)$, which have a hexagonal DO19 structure. Several studies on $\alpha_{2}$ precipitates have been undertaken [5]-[9], but a complete understanding of their nucleation mechanisms and effects on the mechanical properties of the alloy has yet to be achieved.

The precipitation of $\alpha_{2}$ in Ti-Al type alloys is highly dependent on the aluminium content and the annealing conditions, with a minimum aluminium content of approximately 5 wt. $\%$ necessary to initiate $\alpha_{2}$ formation [8], [10]. It has been demonstrated for binary Ti-Al alloys with relatively high Aluminium content (8-10 wt.\%) that the relative intensity of the superlattice reflections increases with Al content, while the precipitate size increases from $2 \mathrm{~nm}$ 
in Ti-8Al alloy to $150 \mathrm{~nm}$ in Ti-10Al [6]. In addition, the shape of $\alpha_{2}$ precipitates also evolves from initially spherical to an ellipsoidal morphology [6]. The majority of the research focussing on $\alpha_{2}$ precipitates in Ti-6Al-4V has been performed at annealing temperatures between 500$600^{\circ} \mathrm{C}$, as the $\alpha_{2}$ solvus temperature was initially reported to be around $550^{\circ} \mathrm{C}[6],[8],[10],[11]$. However, depending on the alloy chemistry $\alpha_{2}$ precipitation can also be found when annealing at higher temperatures [9], [12].

In Ti-Al binary alloys [6], [7], [13], [14] and Ti-6Al-4V [5], [15], $\alpha_{2}$ precipitation has been shown to increase yield strength and Young's modulus but significantly reduce ductility. The existence of $\alpha_{2}$ in Ti-alloys has also been linked to a reduction in low cycle fatigue resistance and increased crack propagation rates [5]-[7], [16]. Moreover, $\alpha_{2}$ precipitates have been shown to have a detrimental effect on the stress corrosion cracking resistance of the alloy and cause substantial hydrogen pick up, which leads to embrittlement [17], [18]. The effect of $\alpha_{2}$ precipitation on mechanical properties has been associated with increased levels of slip planarity. As $\alpha_{2}$ precipitates in commercial alloys are coherent and at the nano-scale, dislocations cut them during plastic deformation enhancing slip localisation.

In hexagonal close-packed (hcp) metals, deformation by slip occurs along the $\langle 11 \overline{2} 0\rangle$ ( $\vec{a}$ type Burgers vector) and the $\langle 11 \overline{2} 3\rangle(\vec{c}+\vec{a}$ type Burgers vector $)$ directions. In the case of Ti, easy slip modes are the $\vec{a}$ type $\langle 11 \overline{2} 0\rangle\{10 \overline{1} 0\}$ prismatic and $\langle 11 \overline{2} 0\rangle(0002)$ basal slip [19]. It has also been suggested that $\langle 11 \overline{2} 0\rangle\{10 \overline{1} 1\}$ slip exists [19] although experimental evidence for it is relatively weak. The $\langle 11 \overline{2} 3\rangle$ slip direction has a $\vec{c}+\vec{a}$ type Burgers vector that is larger than the $\vec{a}$ type Burgers vector and is therefore more difficult to activate. The planes associated with $\vec{c}+\vec{a}$ slip are $\{10 \overline{1} 1\} 1^{\text {st }}$ order pyramidal planes and the $\{11 \overline{2} 2\}$ $2^{\text {nd }}$ order pyramidal planes [19]-[22].

Previous work has shown that $\alpha_{2}$ precipitates promote planar slip along both prismatic $\{10 \overline{1} 0\}$ and basal $\{0002\}$ planes [7], [15], with increasing planarity associated with increasing Al content [7]. TEM investigations have demonstrated dislocations moving in pairs in the presence of $\alpha_{2}$ to minimise the formation of Anti-Phase Boundaries
(APBs) [5], [7], [23]. The APB energy for the respective slip systems was shown to be lower for prismatic type I dislocations compared to basal planes, with higher APB energy for prismatic type II dislocations [7], [1]. If it is assumed that prismatic slip will always choose the lowest APB energy required then this suggests an increased likelihood of slip along the prismatic plane in materials with $\alpha_{2}$ precipitates. Such slip localisation, or slip planarity, then promotes the formation of dislocation pile-ups at the grain boundaries [5]-[7] leading to prime locations for crack nucleation [5], [6], [15]. Moreover, Terlinde et al. have shown that decreasing the grain size in binary Ti8.6Al increases fracture strength and reduces the generation of dislocation pile-ups [23].

More recently, slip trace analysis has been used to identify active slip systems in individual grains by imaging slip traces using Scanning Electron Microscopy (SEM) combined with grain orientation mapping by Electron Backscatter Diffraction (EBSD) [24], [25]. However, while such slip trace analysis can provide information on the relative frequency of the different slip systems, it does not necessarily provide information on the actual shear strain contribution of these slip modes to the overall plastic deformation.

High Resolution Digital Image Correlation (HR-DIC) is a prominent displacement mapping technique that provides experimental data to support linking continuum mechanics and dislocation dynamics [26]-[29]. DIC is a method used to map the displacement of markers on the surface of a strained sample from images acquired at different stages of deformation [26], [27], [29]. To perform a correct crosscorrelation each subset must show unique features, therefore a distinctive pattern is applied to the surface of the specimen. In case of high spatial resolution strain mapping at a scale that enables the analysis of slip traces, vapourassisted remodelling of deposited gold has proven to be a highly effective pattern-forming methodology [27], [30][32]. The two main advantages of this method are the simplicity of creating non-repetitive but homogenous nanoscale patterns over large areas compared to other techniques (i.e. lithography or ion-beam assisted deposition) and the high spatial resolution of the 2D displacement and strain maps that can be achieved from the nano-sized 
speckles [27]. It has been demonstrated that this method provides detailed strain information, as single slip traces can be resolved and can be compared quantitatively to assess the level of strain heterogeneity between samples, slip systems and single grains [27], [32], [33].

The aim of these experiments was to determine whether the effects of $\alpha_{2}$ precipitation on the slip character could be measured using HR-DIC, as they are known to have a detrimental effect on the low cycle fatigue (LCF) behaviour due to an increase in strain localisation [34]. The present work utilises the nanoscale spatial resolution of the HRDIC technique to determine if it is possible to quantify for the first time the differences in strain heterogeneity in a two-phase Ti-alloy with and without $\alpha_{2}$ precipitates. The work also aims at providing new mechanistic insight on the effect of $\alpha_{2}$ formation on the slip mode activity in Ti$6 \mathrm{Al}-4 \mathrm{~V}$ by cross correlating the high resolution strain maps with grain orientation information recorded by EBSD.

\section{Experimental Procedure}

\section{Material}

The material in this study was conventional Ti-6Al-4V that had been provided by Rolls-Royce plc. The material had been forged and annealed, but was not subjected to rolling. It displayed an equiaxed microstructure, a relatively weak texture (less than 2.5 times random) and also low levels of microtexture/macrozones. In order to create a simplified microstructure, samples were first solution heat treated in the $\alpha+\beta$ phase regime followed by $1^{\circ} \mathrm{C} / \mathrm{min}$ cooling. This generates an equiaxed $\alpha$ microstructure with the $\beta$-phase restricted to triple points and a uniform grain size distribution. To compare the effect of $\alpha_{2}$ precipitates on the deformation behaviour, two different ageing treatments were applied. One set of samples was aged at $500^{\circ} \mathrm{C}$ for 24 hours followed by furnace cooling at $1^{\circ} \mathrm{C} / \mathrm{min}$ to promote the formation of $\alpha_{2}$ precipitates. The other set of samples was annealed above the $\alpha_{2}$ solvus temperature at $700^{\circ} \mathrm{C}$ for 2 hours and then water quenched to avoid $\alpha_{2}$ precipitation.
Specimens were machined for tensile testing and microstructural characterisation by electric discharge machining. The recast layer was removed through grinding. The tensile specimens had a flat dog bone geometry with a $26 \mathrm{~mm}$ gauge length; $3 \mathrm{~mm}$ gauge width and were $1 \mathrm{~mm}$ thick. The samples were prepared for HR-DIC studies by initial polishing to \#4000 grit paper and subsequent hand polishing for 1 hour on an OPS cloth in a solution of 4:1 OPS to hydrogen peroxide. After polishing, a series of microhardness indents were made on the surface of the specimen to act as fiducial markers, allowing quick identification of the region of interest.

The regions of interest were fully characterised for both conditions, i.e. with and without $\alpha_{2}$ precipitation, before creating the gold pattern and again imaged after gold patterning in order to record the initial stage prior to deformation. The specimens were then deformed incrementally in tension to approximately $1 \%$ and $5 \%$ applied strain, respectively. The experiments were performed at room temperature and at a strain rate of $0.1 \mathrm{~mm} / \mathrm{min}$ (translating to about $6 \times 10^{-5} \mathrm{~s}^{-1}$ ) using a Kammrath-Weiss $5 \mathrm{kN}$ TensionCompression microtester. After each deformation stage the sample was removed from the microtester and mounted in the FEG-SEM for imaging the gold pattern in the region of interest. The HR-DIC analysis requires images with excellent signal-to-noise ratio, which can only be achieved by using a small working distance $(6 \mathrm{~mm})$ during imaging. As placing the microtester in-situ would have required the use of a working distance in excess of $20 \mathrm{~mm}$, all experiments were performed ex-situ.

\section{Grain orientation mapping}

Grain orientation mapping in the regions of interest was performed using a field emission gun (FEI Quanta 650) SEM equipped with an AZtec EBSD system and a Nordlys II detector. EBSD scans were performed at an operating voltage of $20 \mathrm{kV}$. An area of $0.5 \times 0.5 \mathrm{~mm}^{2}$ was analysed to identify suitable regions for HR-DIC using a step size of $0.5 \mu \mathrm{m}$, which is about $1 / 20$ of the average grain size. Macrotexture analysis was carried out on area of $4 \times 4 \mathrm{~mm}^{2}$ with a step size of $5 \mu \mathrm{m}$. The data (confidence index $>0.1$ ) were analysed and plotted using HKL Channel $5^{\mathrm{TM}}$ software [35]. 
Transmission Electron Microscopy (TEM)

Samples for Transmission Electron Microscopy (TEM) were prepared from both heat-treated conditions by initially polishing samples to a thickness of approximately 200 $\mu \mathrm{m}$ using \#800 grit paper. Subsequently, $3 \mathrm{~mm}$ discs were extracted before final thinning to a thickness of about 120 $\mu \mathrm{m}$. The final step was electro polishing using a twinjet electro polisher with a Julabo FP50 cooling unit. The electrolyte used here was perchloric acid $(50 \mathrm{ml} / \mathrm{L})$ and ethanol $(950 \mathrm{ml} / \mathrm{L})$, at a temperature of $-21^{\circ} \mathrm{C}$ and a voltage of 40 V.

Thin-foil specimens were analysed using an FEI ${ }^{\circledR}$ Tecnai ${ }^{\circledR} \quad$ G2 20 TEM equipped with DITABIS ${ }^{\circledR}$ highresolution imaging plates to identify the presence of $\alpha_{2}$ precipitates. Selected area electron diffraction patterns (SAEDPs) were collected from the $<11 \overline{2} 0>$ zone axis with a sufficiently long exposure time (i.e. $60 \mathrm{~s}$ ) to enable the visualisation of superlattice reflections from $\alpha_{2}$ precipitates.

\section{Gold Remodelling}

After EBSD mapping a gold speckle pattern was applied to the surface of each sample using the gold remodelling technique [27]. Initially, a gold layer of 25-40 nm was deposited on to the surface of the sample using an Edwards S150B sputter coater at a deposition rate of $5-8 \mathrm{~nm} / \mathrm{min}$. The remodelling was performed by placing the sample on a hot plate between a water vapour source and an inverted beaker at a temperature of $250-300^{\circ} \mathrm{C}$. The ideal pattern has a uniform distribution of speckle size to spacing. Great care was taken during the preparation as surface finish and polishing conditions can have significant impact on the resultant speckle pattern [27].

\section{$\underline{\text { High Resolution Digital Image Correlation (HR-DIC) }}$}

The HR-DIC images were acquired using an FEI Quanta 650 FEG-SEM in back-scattered electron (BSE) imaging mode to obtain high contrast between the speckle pattern and the substrate [31]. BSE imaging is also less sensitive to topographic features at the sample surface than secondary electron (SE) imaging, thus reducing any correlation problems caused by slip in the out-of-plane direction [36]. Images were acquired at $20 \mathrm{kV}$ with a working distance of less than $6 \mu \mathrm{m}$, at magnifications giving horizontal field widths of $37.6 \mu \mathrm{m}$. Each image took 2 minutes to record and all images were acquired at a resolution of $2048 \mathrm{x}$ 1768 pixels $^{2}$ in a scan mode with a $30 \mu$ s dwell time. The total area analysed by HR-DIC was composed of an array of 4 x 4 images, which covers an area of approximately $120 \times 100 \mu \mathrm{m}^{2}$. No drift correction was applied to the images due to sub-pixel beam position shifts having only a minor effect on the systematic error. The systematic error was calculated by comparing two images from the same region before deformation and then using decreasing interrogation window sizes to find the optimal interrogation window to perform the strain analysis [27].

DIC is essentially the tracking of features from the same area before and after deformation. For each sample, the full array of images of the specimen before deformation was correlated with the images acquired at each deformation stage, generating individual strain maps that were stitched together post processing. The HR-DIC analysis was performed using the commercially available La Vision's DaVis imaging software [37]. Initially, the images were shift corrected to align the central features for each deformation step. The local displacement was calculated by applying a standard fast Fourier transformation (FFT) cross correlation relative to the first image.

\section{$\underline{\text { Slip Trace Analysis }}$}

Slip trace analysis was performed based on the slip traces recorded by HR-DIC in combination with grain orientation mapping by comparing the theoretical slip trace angle for all slip systems with the experimentally determined slip trace angle of individual grains. The theoretical slip trace angles were calculated using a crystal mathematical tool developed by Brad Wynne at The University of Sheffield. The tool uses the average Euler angles for individual grains, which were first extracted from EBSD data using a MATLAB ${ }^{\circledR}$ script. The experimentally observed slip trace angles were measured using the software package ImageJ by selecting two points along the length of the predominant slip trace within each grain. When comparing the theoretical and experimental slip trace angles, an angle matching criterion of $\pm 5^{\circ}$ was used to determine the likely slip system. For grains predicted to deform by basal slip, the slip direction with the highest global Schmid factor 
was assumed to be the active slip system associated with that particular trace. As slip trace analysis cannot distinguish between $\vec{a}$ and $1^{\text {st }}$ order $\vec{c}+\vec{a}$ pyramidal slip they are portrayed here as general pyramidal slip. If more than one slip system matched the angle criterion, equation 1 was used to estimate the most likely slip mode, which calculates a normalised Schmid factor $\mathrm{m}_{\mathrm{n}}$ by dividing the Schmid factor determined by EBSD analysis $\left(\mathrm{m}_{0}\right)$ using a relative CRSS value of 1 for prismatic and basal slip and 3 for pyramidal slip. This CRSS ratio is based on CRSS values determined in [21], [38], [39]. Although this approach is not conclusive it does provide a satisfactory method of including all grains within the analysis. About $10 \%$ of the analysed slip traces had to be estimated using equation 1 .

$m_{n}=\frac{m_{o}}{\text { CRSS ratio }} \quad$ Equation 1

\section{Results}

\section{Material characterisation}

Figure 1 shows subsection band contrast maps of the two microstructural conditions recorded by EBSD. The images demonstrate an equiaxed $\alpha$ microstructure for both conditions with retained $\beta$ (brighter phase) predominantly sitting in the triple points. Using the open source software ImageJ and the ASTM standard analysis techniques [40] gave an $\alpha$ grain size of about $10 \mu \mathrm{m}$ and a retained $\beta$ volume fraction of about $10 \%$. Figure 1 also includes (0002) and $\{10 \overline{1} 0\}$ pole figures demonstrating a relatively weak texture with maximum intensities between 2.0 and 2.5 times random for the (0002) pole figure.

\section{Identification of $\alpha_{2}$ precipitation}

Figure 2 shows the SAEDPs that were collected from the $<11$ 20> zone axis on thin-foil TEM specimens from the materials that were annealed to avoid $\left(2\right.$ hours at $\left.700^{\circ} \mathrm{C}\right)$ and promote $\left(24\right.$ hours at $\left.500^{\circ} \mathrm{C}\right) \alpha_{2}$ precipitation, respectively. Figure $2 \mathrm{a}$ confirms that the high temperature anneal indeed did not result in any $\alpha_{2}$ precipitation whereas relatively diffuse $\alpha_{2}$ superlattice reflections can be observed in the SAEDP after the low temperature anneal, Figure $2 b$. (a)

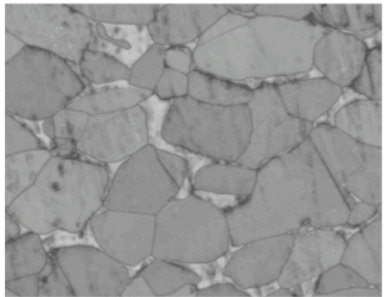

(b)

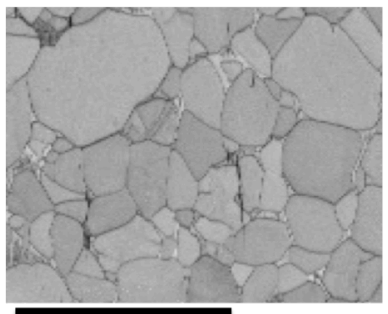

$50 \mu \mathrm{m}$
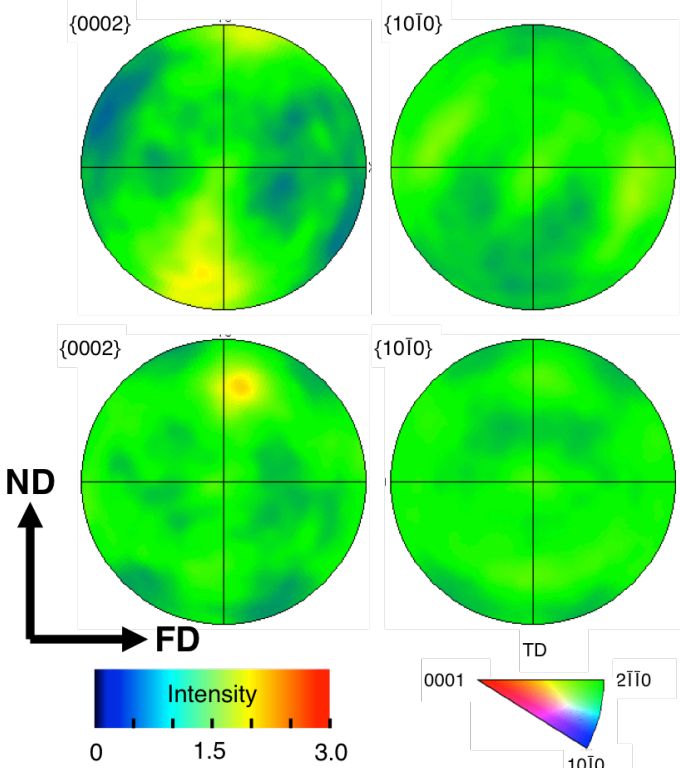

Figure 1 - Band contrast maps of HR-DIC region for (a) No $\alpha_{2}$ precipitates and (b) $\alpha_{2}$ precipitates. EBSD generated $\{0001\}$ and $\{10 \overline{1} 0\}$ pole figures of the macrotexture from a region of $4 \times 4 \mathrm{~mm}^{2}$ are shown on the right side of each figure. For interpretation of the references to the colour in this figure legend the reader is referred to the web version of this article 

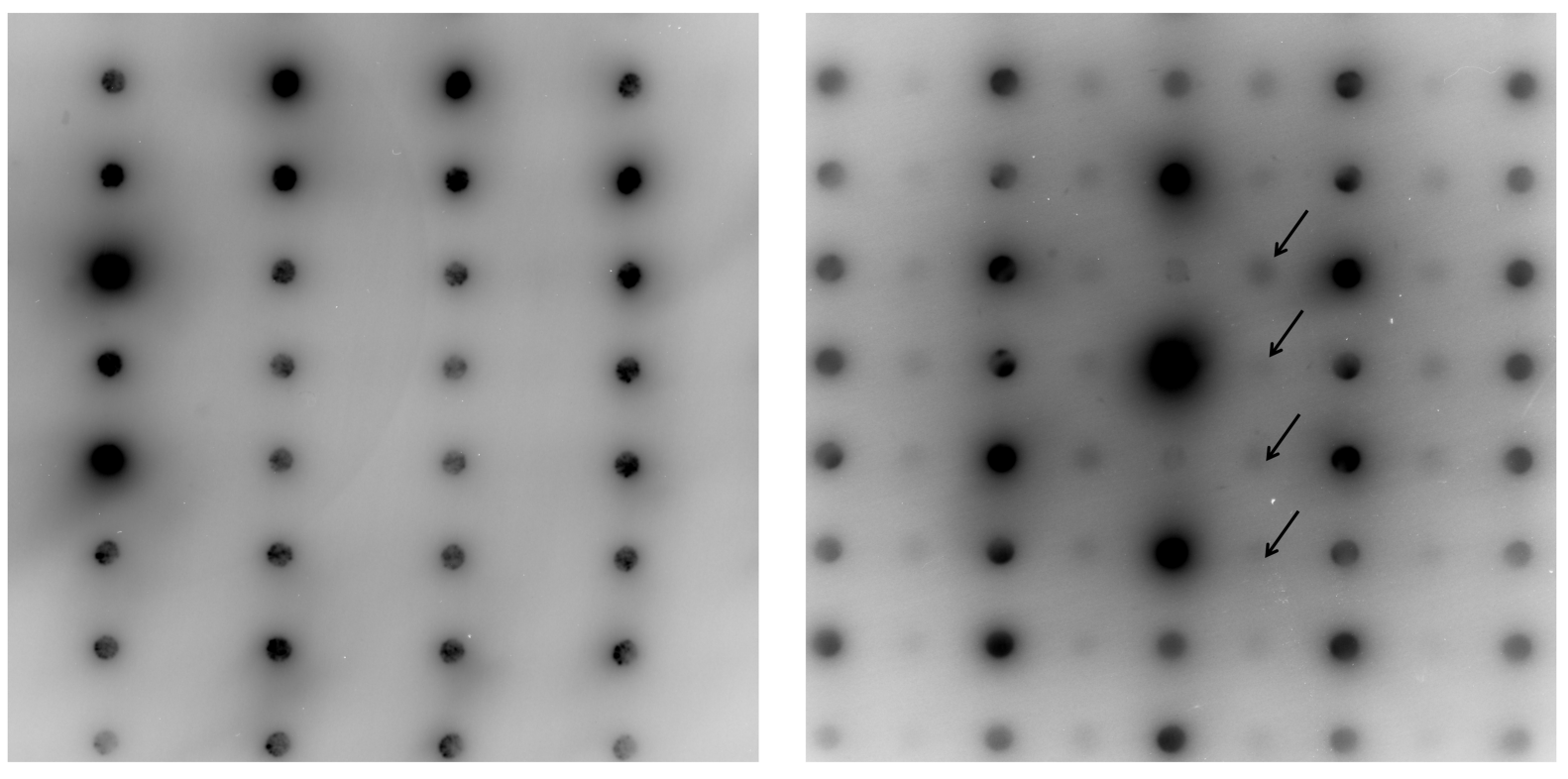

$51 / \mathrm{nm}$

Figure 2 - SAEDPs from the $<11 \overline{20}>$ zone axis for the (a) no $\alpha_{2}$ precipitates and (b) $\alpha_{2}$ precipitates. The intensity scales were inverted to highlight the superlattice reflections (marked by arrows)

\section{D shear strain analysis}

The maps obtained by HR-DIC are presented here in terms of maximum shear strain maps in order to take into account all in-plane strain components [27], [41]. The maximum shear strain $\left(\varepsilon_{\max }\right)$ was calculated using equation 2 , where $\varepsilon_{\mathrm{xx}}$ is the strain in the loading direction, $\varepsilon_{\mathrm{yy}}$ is the in-plane strain normal to the loading direction and $\varepsilon_{\mathrm{xy}}$ is the in-plane shear strain.

$\varepsilon_{\max }=\sqrt{\left(\frac{\varepsilon_{x x}-\varepsilon_{y y}}{2}\right)^{2}-\varepsilon_{x y}^{2}} \quad$ Equation 2

The applied plastic strain as a result of the tensile test was approximated for the region of interest by calculating the average $\varepsilon_{\mathrm{xx}}$ across all images.

The speckle pattern morphologies produced by the gold remodelling process are strongly influenced by the previous polishing stage [27]. Despite polishing samples using similar conditions, slight differences were observed in the speckle pattern morphologies for the samples with no precipitates and with precipitates. Figure 3 shows the distinct speckle pattern morphologies and associated frequency distributions of the schematic error associated with interrogation window sizes ranging from $4 \times 4$ pixels ${ }^{2}$ to $12 \mathrm{x}$ 12 pixels $^{2}$ for the strain in the loading direction. The schematic error was calculated for $\varepsilon_{\mathrm{xx}}$, as this is the com-

ponent associated with the maximum error. The speckle pattern morphology for the sample without $\alpha_{2}$ precipitates was mesh-like with no clear separation between the gold islands, but with a clear contrast between the gold and the substrate, Figure $3 \mathrm{a}$. In comparison, Figure $3 \mathrm{~b}$ shows that the sample with $\alpha_{2}$ precipitates had a pattern with individual gold speckles and clear contrast between the speckles and the substrate. Despite the different speckle pattern morphologies the systematic error distributions for the same interrogation window size are very similar, which confirms comparable spatial resolution for a given window size and validates comparing strain maps between the two material conditions. A distinct narrow distribution is seen for both conditions when using a coarse interrogation window size and this distribution becomes broader as the interrogation window is reduced. To provide the optimal balance between spatial resolution and data reliability, an interrogation window size of $8 \times 8$ pixels $^{2}$ was chosen. This equates to an interrogation window size of $147 \times 147$ $\mathrm{nm}^{2}$. The patterns of the two microstructures were resolved at the same spatial resolution to provide a coherent and reliable comparison between the material conditions. 
(a)

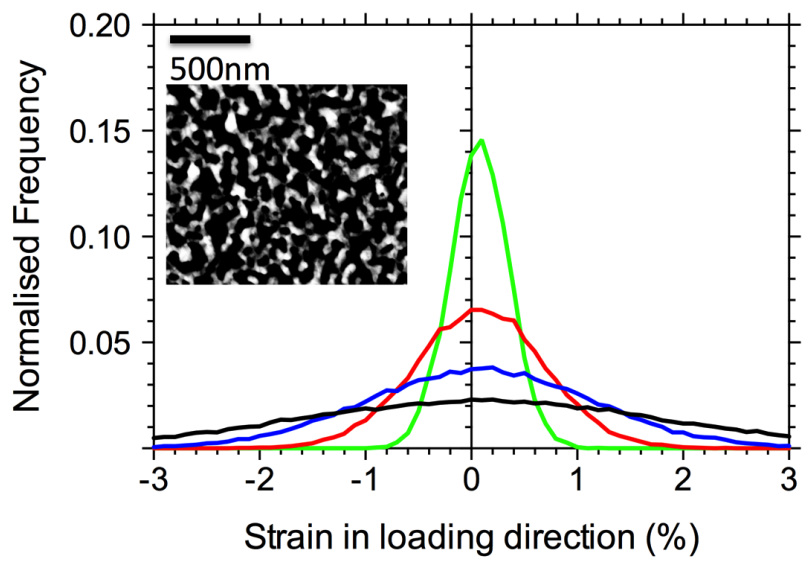

(b)

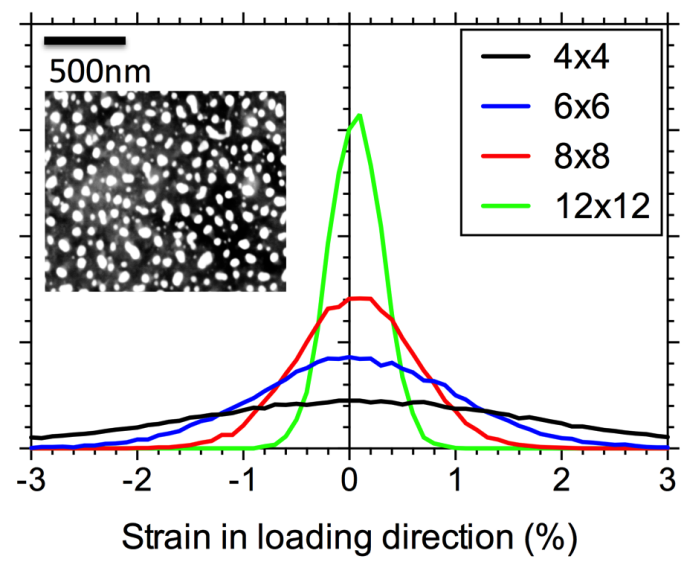

Figure 3 - Back-scattered electron images of the gold speckle pattern and frequency distributions of the error in strain in the loading direction at various interrogation windows sizes for (a) No $\alpha_{2}$ precipitates and (b) $\alpha_{2}$ precipitates

The maximum shear strain maps for both microstructural conditions after a nominal $1 \%$ and $5 \%$ plastic strain are shown in Figure 4. The average $\varepsilon_{\mathrm{xx}}$ strain calculated from HR-DIC strain maps was $0.95 \%$ and $4.42 \%$ for the sample heat-treated to have no $\alpha_{2}$ precipitates and $0.99 \%$ and $4.96 \%$ for the sample with $\alpha_{2}$ precipitates. It should also be noted that the two agglomerated regions with high strain intensities were a result of contamination on the surface of the sample and the strain measurements in these regions were masked out during further data analysis. After $1 \%$ applied strain both microstructures exhibit some grains with intense slip traces while other grains only show slip traces of low intensity or no slip traces at all, Figure $4 \mathrm{a}$ and $\mathrm{b}$. The slip lines in the deformed grains are typically finely spaced and display planarity. For the $\alpha_{2}$-free microstructure maximum shear strains of $15 \%$ were recorded while the microstructure containing $\alpha_{2}$ showed higher maximum levels exceeding 20\%. After 5\% macroscopic strain, both microstructures again seem to display similar strain patterns, Figure $4 \mathrm{c}$ and $\mathrm{d}$. The two main characteristics of these two maps is the development of new slip bands and significant shear strain intensification within shear traces that were already observed after $1 \%$ applied strain. The maxi- mum shear strains observed in both microstructures are over $40 \%$ and the majority of the grains now show clear slip band formation. However, there are a few grains that still exhibit more homogeneous strain distributions with relatively low and diffuse slip. These grains generally appear close to grains that show intense slip bands.

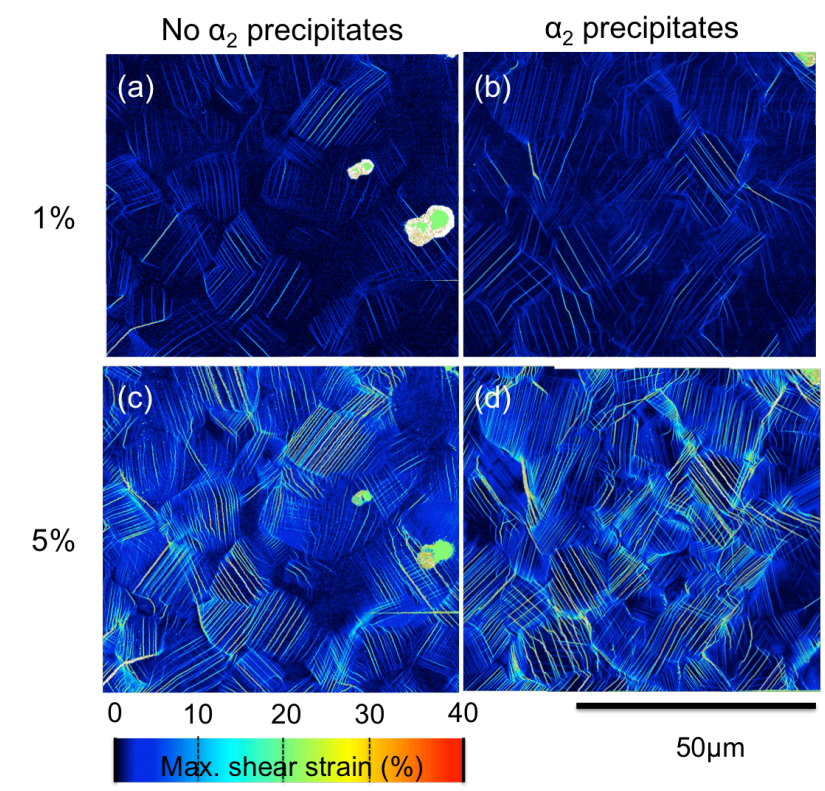

Figure 4- HR-DIC maps of maximum shear strain at $1 \%$ plastic strain for (a) No $\alpha_{2}$ precipitates and (b) $\alpha_{2}$ precipitates and at $5 \%$ plastic strain for (c) No $\alpha_{2}$ precipitates and (d) $\alpha_{2}$ precipitates. The two agglomerated regions with high strain intensity are due to contamination on the surface of the sample. 
Since the slip traces with the highest shear strain might eventually lead to failure of the material, a minimum threshold shear strain of $10 \%$ for the $1 \%$ applied strain maps and $40 \%$ for the $5 \%$ applied strain maps was applied and the maps were replotted, see Figure 5. This highlights that after $1 \%$ plastic strain, only 22 high shear strain slip traces are observed in the $\alpha_{2}$-free sample, Figure $5 \mathrm{a}$, whereas the area of the sample with $\alpha_{2}$ precipitates features 37 high shear strain slip traces, Figure 5 b. It also appears that in the sample with $\alpha_{2}$ precipitates a larger number of grains have deformed by highly localised shear strain compared to the $\alpha_{2}$-free sample. Comparing the thresholded strain maps at $5 \%$ macroscopic strain once again shows fewer high shear strain slip traces for the $\alpha_{2}$-free sample, Figure 5c, with 26 high shear strain slip traces observed compared to 43 slip traces in the $\alpha_{2}$ precipitates sample, Figure $5 \mathrm{~d}$. Once again, more grains appear to have deformed by high shear strain in the sample with $\alpha_{2}$ precipitates compared to the one free of $\alpha_{2}$.
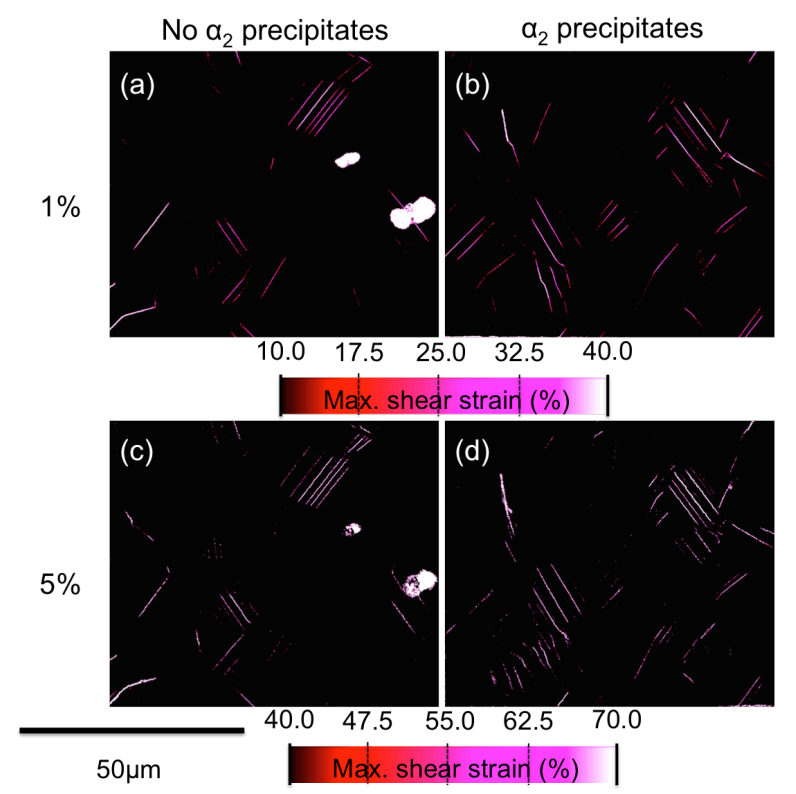

Figure 5- Thresholded HR-DIC maps of maximum shear strain at $1 \%$ plastic strain (above 10\%) for (a) No $\alpha_{2}$ precipitates and (b) $\alpha_{2}$ precipitates and at $5 \%$ plastic strain (above $40 \%$ ) for (c) No $\alpha_{2}$ precipitates and (d) $\alpha_{2}$ precipitates

\section{Slip system activity}

As only a relatively small area and hence small number of grains was investigated, it is important to identify any pos- sible local texture effects on the measured strain maps. For this reason, Schmid factor maps have been plotted for prismatic $\vec{a}$ and basal $\vec{a}$ slip and are compared to the shear strain maps. It should be noted that the consideration of a Schmid factor in a polycrystalline material gives only an approximate prediction of the likely slip system within each grain as it based on the applied stress and does not take into account the local stress state or grain-to-grain strain compatibility. Figure 6 shows these maps for the sample without $\alpha_{2}$ precipitation. Comparing the two Schmid factor maps, Figure $6 a$ and $b$, it is clear that most grains are favourably orientated for prismatic slip. The most intense slip traces after $1 \%$ plastic strain are associated with grains very well aligned for prismatic slip (circled red in Figure 6c) and to a slightly lesser agree with a grain well aligned for basal slip (circled purple in Figure $6 \mathrm{c}$ ). Figure $6 \mathrm{~d}$ shows that at $5 \%$ applied strain intense shear strain traces are not only constrained to grains with high Schmid factors for $\vec{a}$ slip anymore. It can also be noted that some high shear strain regions coincide with grain boundaries between grains with high misorientation, which are indicated by red arrows.

Figure 7 is the same arrangement of representations as in Figure 6 but for the sample with $\alpha_{2}$ precipitates. When comparing the Schmid factor maps for the two microstructureconditions it becomes clear that the region studied in the sample with $\alpha_{2}$ precipitates tends to have far fewer grains well aligned for prismatic slip but more for basal slip. Again, intense shear strain is mainly associated particularly with grains well aligned for prismatic (circled red in Figure 7c) slip and to a lesser degree to grains well aligned for basal slip (circled purple in Figure 7c) at 1\% macroscopic strain. Once again, intense slip traces are not constrained only to grains with high Schmid factors for $\vec{a}$ type slip after $5 \%$ applied strain, as shown in Figure $7 \mathrm{~d}$. 


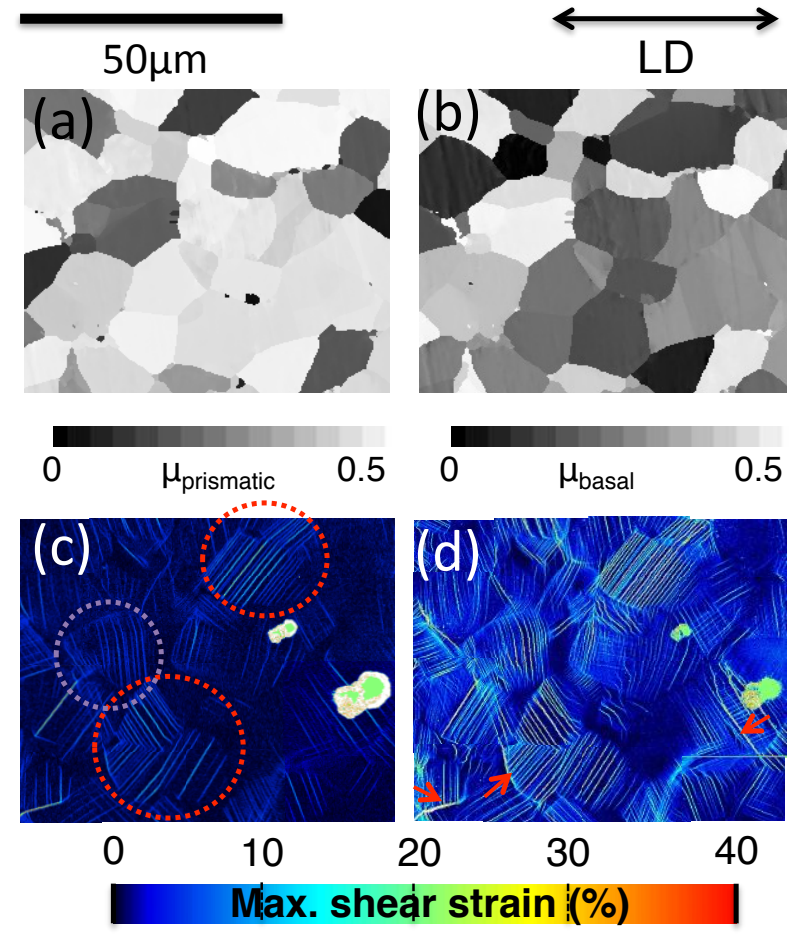

Figure 6- Comparison of Schmid factor maps generated from EBSD orientation data for (a) prismatic and (b) basal from the HR-DIC maps of maximum shear strain at (c) $1 \%$ and (d) $5 \%$ plastic strain for the sample with no $\alpha_{2}$ precipitates
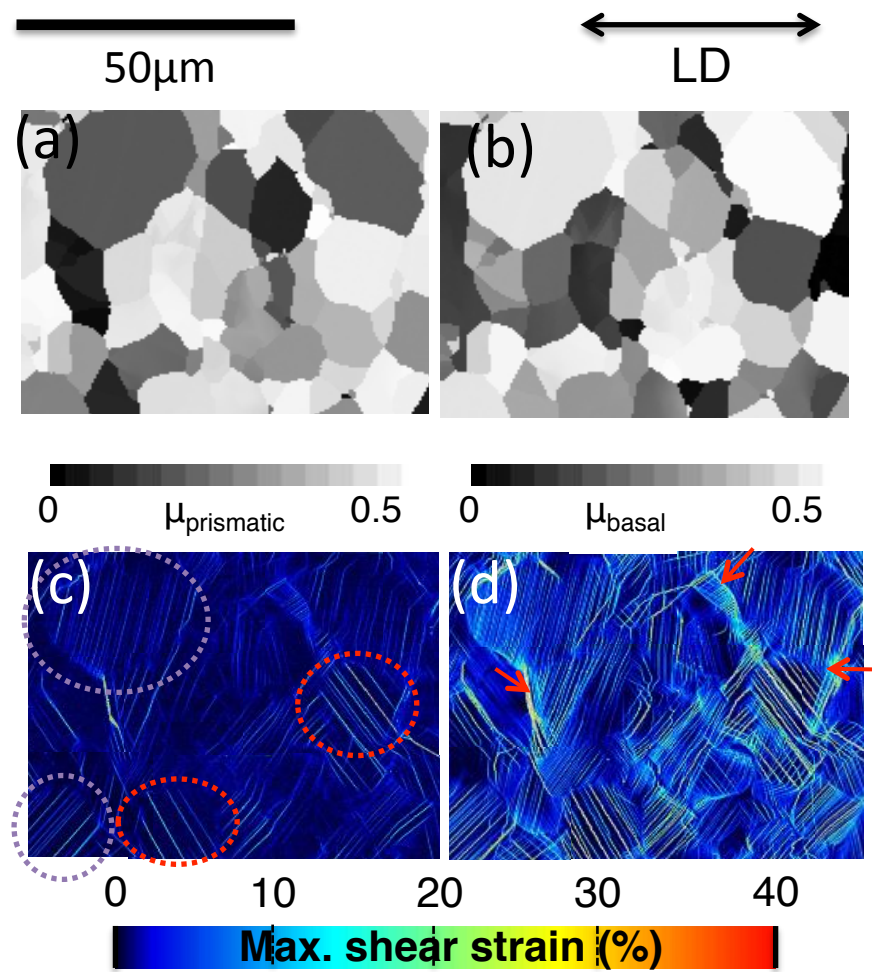

Figure 7- Comparison of Schmid factor maps generated from EBSD orientation data for (a) prismatic and (b) basal from the HR-DIC maps of maximum shear strain at (c) $1 \%$ and (d) $5 \%$ plastic strain for the sample with $\alpha_{2}$ precipitates
To provide a more accurate prediction of slip system activity, slip trace analysis was performed by cross correlating the results of theoretical slip trace angle predictions based on the grain orientation maps with the experimentally determined slip trace angles from the HR-DIC maps. Figure 8a and $b$ display the Schmid factor distributions for prismatic $\vec{a}$ and basal $\vec{a}$ slip of the regions studied for the two different microstructure conditions. These are compared to frequency histograms of active slip systems (predicted using slip trace analysis) as a function of the Schmid factor in Figure $8 \mathrm{c}$ and $\mathrm{d}$. In addition, the number of active grains for each slip system is summarised in the respective legends in Figure $8 \mathrm{c}$ and $\mathrm{d}$. The number of grains analysed was 44 in the case of the $\alpha_{2}$-free condition and 56 grains for the sample with $\alpha_{2}$ precipitates. Figure $8 \mathrm{c}$ and $\mathrm{d}$ show that prismatic slip is by far the most common slip mode in the region interrogated for the sample without $\alpha_{2}$ precipitation while in the region of the sample with $\alpha_{2}$ precipitation prismatic and basal slip are equally frequent. However, this difference in slip type activity is not necessarily related to the presence or absence of $\alpha_{2}$ phase but most likely due to the difference in the grain orientation distribution, as shown in Figure $8 \mathrm{a}$ and $\mathrm{b}$. It can also be noted that for both microstructures pyramidal slip is by far the least frequent slip mode, which is expected assuming that the observed pyramidal slip is of the $\vec{c}+\vec{a}$ type, which is known to have a significantly higher CRSS value than $\vec{a}$ type slip. 
(a)

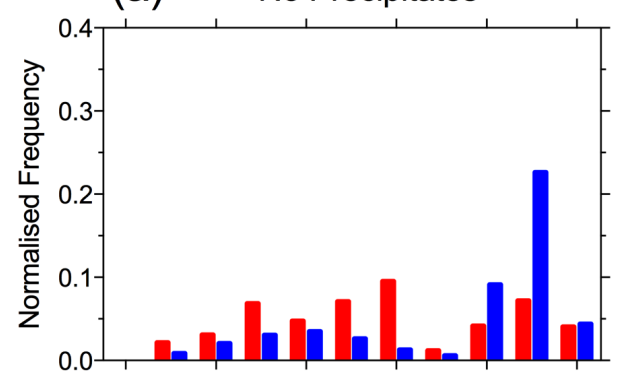

(c)

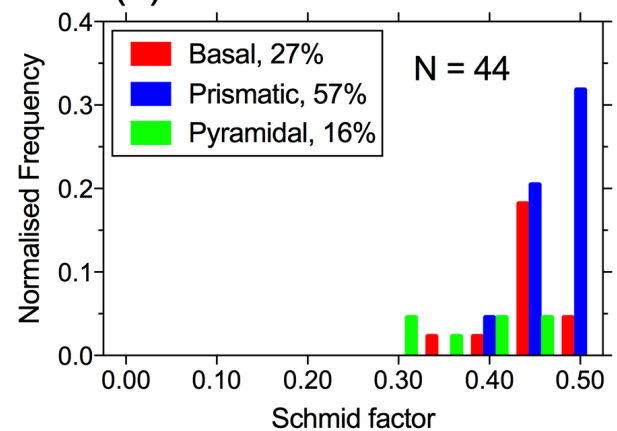

(b) Precipitates

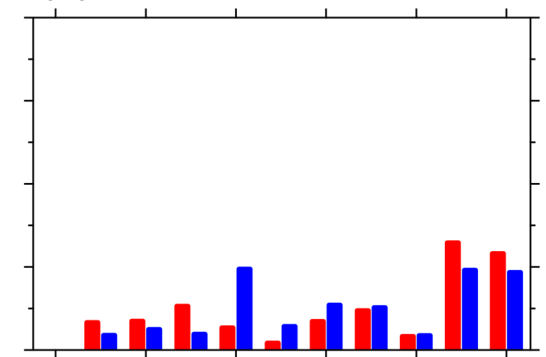

(d)

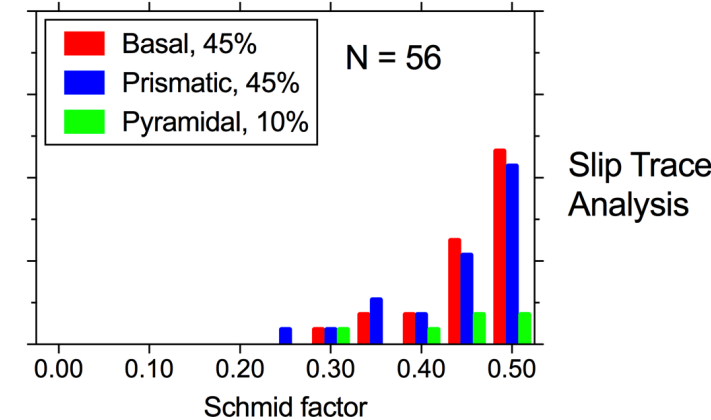

Figure 8- Histograms of the global Schmid factor distributions as determined from EBSD orientation (theoretical) data for basal and prismatic slip for (a) no $\alpha_{2}$ precipitates and (b) $\alpha_{2}$ precipitates and Schmid factor distributions of the active slip systems (as predicted using slip trace analysis) for basal, prismatic and pyramidal slip at $\sim 5 \%$ strain for (c) no $\alpha_{2}$ precipitates and (d) $\alpha_{2}$ precipitates

\section{Discussion}

Whilst it is well known that deformation in most engineering alloys is highly heterogeneous through slip band formation [42], high-resolution strain mapping using DIC opens up the possibility to quantify the level of strain localisation during plastic deformation and hence compare different alloys and microstructural conditions in terms of strain heterogeneity. In the present work, the gold remodelling technique has been used to produce nanoscale patterns, which, in combination with SEM imaging, allows sub micron resolution strain measurements that give detailed information on the strain concentrations within single grains relative to each other and the variations across many grains. As there is not a single grain in a polycrystalline material with the same neighbourhood as another grain, statistical analysis of such data is of great importance. Therefore, Figure 9 compares frequency distributions of the maximum shear strain (binning size of $0.5 \%$ ) for the two microstructural conditions after $1 \%$ and $5 \%$ plastic deformation, respectively. The maximum shear strain values have been normalised by dividing them by the averaged $\varepsilon_{\mathrm{xx}}$ strain across the entire map, as calculated from the HR-DIC data, in order to take into account the slight differences in macroscopic strain between the two samples. Figure 9 a demonstrates that at $1 \%$ plastic strain the sample with $\alpha_{2}$ precipitates tends to have slip traces that generate larger shear strain than the sample without $\alpha_{2}$ precipitates. Importantly, the maximum shear strain value (at a frequency of $0.1 \%$ ) is almost twice in the sample with $\alpha_{2}$ compared to the one without it. In other words, at $1 \%$ plastic strain $\alpha_{2}$ precipitates seem to enhance strain localisation. When comparing maximum shear strain to average macroscopic strain the ratio reached in the $\alpha_{2}$-containing sample is about 20 , while in the $\alpha_{2}$ free sample this ratio is only 11-12. Previous studies using HR-DIC with a similar spatial resolution in austenitic stainless steel [27] and titanium [32] have shown peak-to-applied strain ratios of $\approx 10$, which is in agreement with the observations for the $\alpha_{2}$-free sample. However, the higher peak-to-applied strain ratio observed in the sample with $\alpha_{2}$ precipitates is likely to be a result of increased slip planarity and shearing associated with the precipitates [5]-[7]. However, Figure $9 b$ demonstrates that at higher (5\%) plastic strain the $\alpha_{2}$ precipitates and $\alpha_{2}$-free samples have slip traces that generate similar shear strain intensities. When comparing maximum shear strain to average macroscopic strain the ratio reached in both samples is about 13-14. This indicates that at 5\% plastic strain the effect of the $\alpha_{2}$ precipitates on the strain localisation diminishes. 
(a)

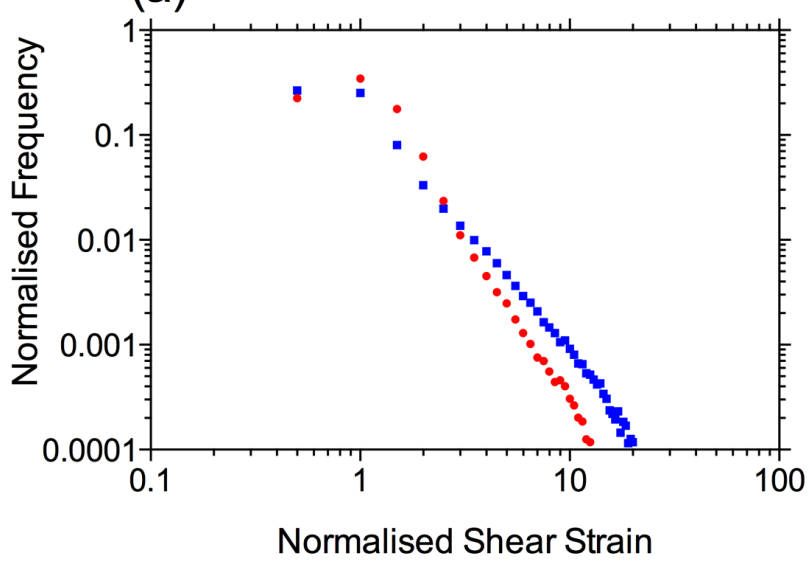

(b)

$5 \%$

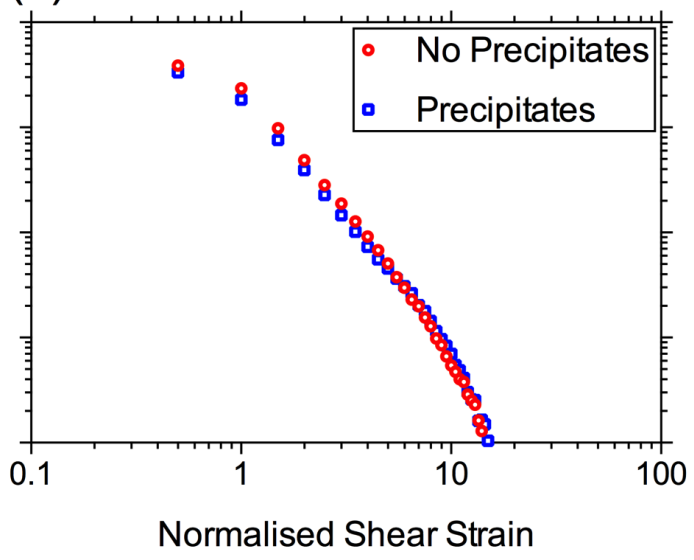

Figure 9- Normalised frequency distributions of the maximum shear strain from HR-DIC data for the no $\alpha 2$ precipitate and $\alpha 2$ precipitate samples at (a) $1 \%$ and (b) $5 \%$ applied strain

The slip trace analysis by HR-DIC in combination with EBSD demonstrates that the observed shear strain traces can be associated with one of the established slip modes in $\mathrm{Ti}$ when using acceptance angles of $5^{\circ}$. However, as more than one slip system may lie within $\pm 5^{\circ}$, caution may be required in slip mode identification presented here until TEM analysis has confirmed the findings by HR-DIC. Despite such concerns, the trends observed here for the active slip systems relative to Schmid factor are in agreement with those observed in previous studies on Titanium alloys [25], [43]-[45]. CP-Ti [44] shows less basal slip with more grains deforming by prismatic slip and twinning than in the current work. While the absence of twinning in Ti-6Al$4 \mathrm{~V}$ can be attributed to the high Al content [39], [46], the difference in slip mode dominance is not necessarily a result of different alloy chemistry but can be attributed to differences in starting texture and loading direction. Indeed, the work here highlights the importance of considering the starting texture when studying effect of alloy chemistry on slip modes in Ti-alloys.

The difference in local texture between the two material conditions in the present work has strongly influenced the slip system activity across the analysed regions, as shown in Figure 8. In the $\alpha_{2}$-free sample, there was a strong dominance for prismatic slip as the majority of grains in the studied region are well aligned for this slip system. This particular region also appears to show a number of neighbouring grains with a similar crystallographic orientation (high Schmid factor for prismatic slip, see Figure 6a), which is expected to reduce the constraint on these grains and promote early slip. In contrast, for the sample with $\alpha_{2}$ precipitates, a similar number of grains deformed by basal relative to prismatic slip, which can be related to the studied region having much more a mixture of grains well aligned for either basal or prismatic slip, see Figure $7 \mathrm{a}$ and $\mathrm{b}$ and Figure $8 \mathrm{~b}$ and $\mathrm{d}$. It is also noticeable that the stronger microtexture in the case of the $\alpha_{2}$-free sample has resulted in prismatic slip trace formation occurring exclusively in grains with Schmid factors of at least 0.4 while a broader spread is observed for the sample with $\alpha_{2}$ precipitates.

An advantage of the use of HR-DIC for slip trace analysis is that, rather than a simple frequency analysis, the shear strain contributions from each slip system can be compared, as demonstrated in Figure 10. Here, the average shear strains associated with a slip mode within individual grains are plotted against the Schmid factor. The analysis highlights that both material conditions display a trend of higher shear strains related to prismatic slip than basal slip, at $1 \%$ and $5 \%$ applied strain, despite the different microtextures. It is worth noting that the two grains in the $\alpha_{2}$-free sample showing particular high shear strain are associated with grains having a high Schmid factor for prismatic slip.

Combining the slip trace analysis and HR-DIC-based strain mapping also enabled to quantify strain heterogeneity for individual slip system, i.e. prismatic, basal and pyramidal slip. As for Figure 9, the measured shear strain was normalised by considering the slightly different levels of $\varepsilon_{\mathrm{xx}}$ strain in the interrogated region when comparing the two material conditions. The data are presented in Figure 11 
using a bin size of $0.5 \%$ shear strain. Figure 11a shows that at $1 \%$ applied strain no significant difference in the frequency distributions for the three different slip modes is detected in the $\alpha_{2}$-free sample with maximum normalised shear strains reaching $8 \%, 9 \%$ and $10 \%$ for pyramidal, basal and prismatic slip at a frequency of $0.01 \%$. In contrast, Figure $11 \mathrm{~b}$ demonstrates clear differences for pyramidal, basal and prismatic slip with maximum normalised shear strain values of $5 \%, 8 \%$ and $15 \%$. Figure $11 \mathrm{c}$ and $\mathrm{d}$ show that the trends remain at 5\% applied strain with the difference in heterogeneity for the respective slip systems reducing further for the $\alpha_{2}$-free sample, while prismatic slip continues to be the most shear strain intense slip system for the sample containing $\alpha_{2}$ precipitates. However, the level of heterogeneity for the respective slip systems is less pronounced with maximum normalised shear strains of $6 \%, 8 \%$ and $10 \%$ for pyramidal, basal and prismatic slip, respectively. Hence, while the investigated region of the $\alpha_{2}$-containing sample does show a high number of basal slip traces, which can be explained by the microtexture, the actual shear strain related to prismatic slip is still enhanced by the presence of $\alpha_{2}$ precipitates. Figure 11 also enables a more quantitative analysis of strain heterogeneity between microstructures and slip systems by calculating the gradient of the linear portion of the log-log frequency distributions, providing data found in Table 1 . Here, a shallower angle, and hence less negative number, indicates higher strain heterogeneity. This provides a statistical method of characterising the level of strain heterogeneity from the HR-DIC strain maps that could then be used to compare the deformation behaviour across different materials and microstructures and possibly act as a parameter for predicting a materials relative susceptibility to different environments and loading conditions. In the current work, the shallowest gradient is observed at $1 \%$ applied strain for prismatic slip in the $\alpha_{2}$-containing sample (-1.68), suggesting that this is the most heterogeneous condition whereas the gradients for the other slip systems are significantly steeper (i.e. more homogeneous). In comparison, the gradients for the slip modes in the $\alpha_{2}$-free sample are steeper and more similar at $1 \%$ applied strain. The results presented show how although the frequency of easy slip is more strongly related to texture than the presence of $\alpha_{2}$, slip heterogeneity is enhanced by the presence of $\alpha_{2}$. The present observations agree with the observation by Blackburn et al. [7] of slip occurring predominantly along the prismatic plane in materials with $\alpha_{2}$ precipitates but in a more quantitative way. 
(a)

No Precipitates

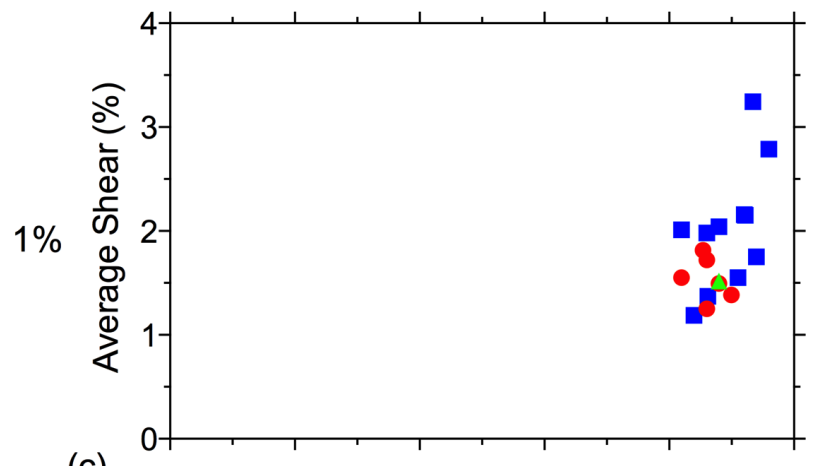

(c)

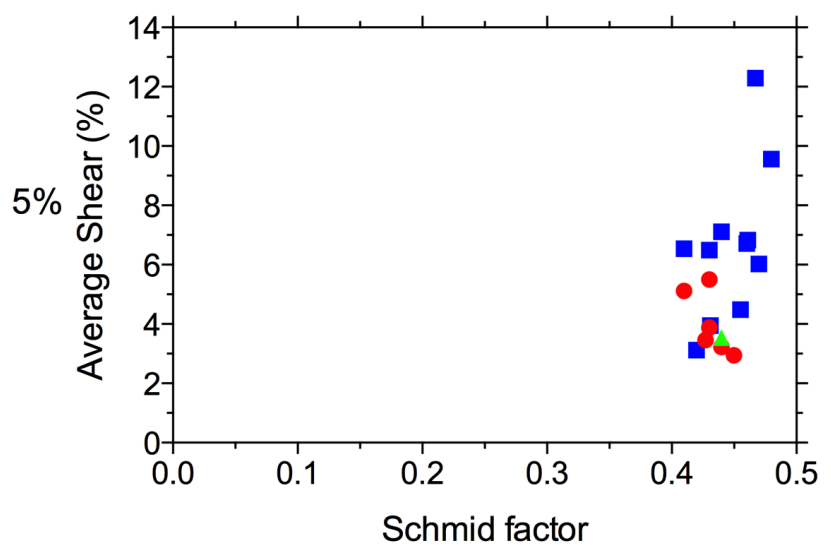

(b)

Precipitates (d)
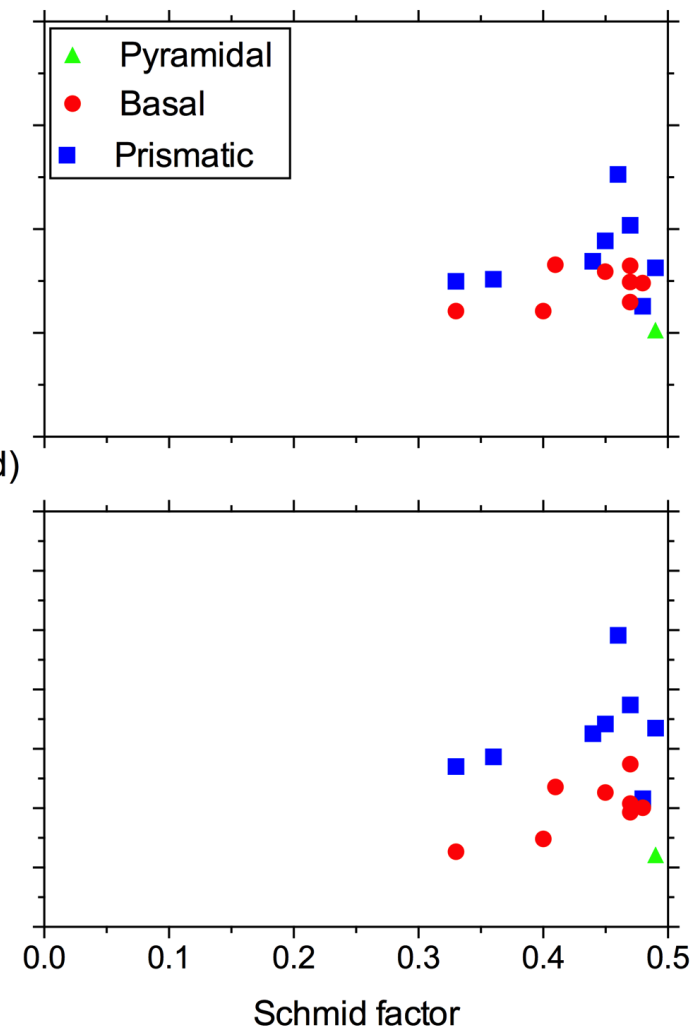

Figure 10- Comparison of the average maximum shear strain in each grain with Schmid factor for basal, prismatic and pyramidal slip at $1 \%$ applied strain for (a) no $\alpha_{2}$ precipitates and (b) $\alpha_{2}$ precipitates and at $5 \%$ applied strain for (c) no $\alpha_{2}$ precipitates and (d) $\alpha_{2}$ precipitates

(a)

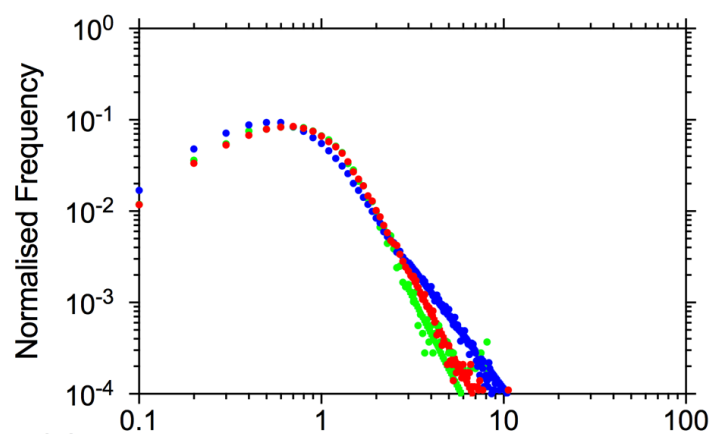

(c)

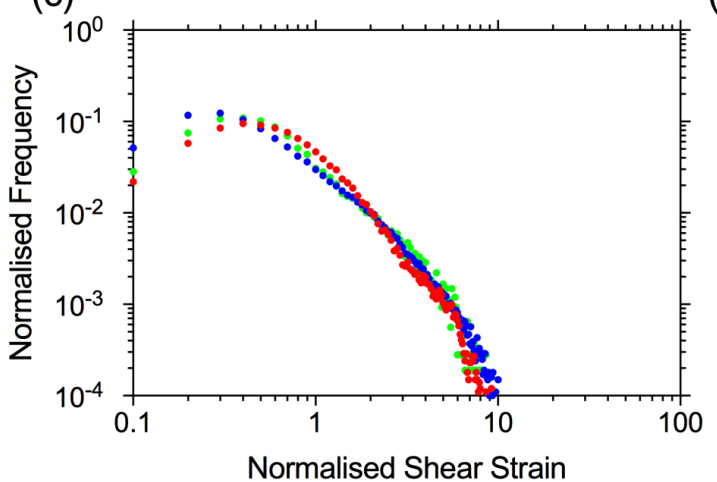

(b)

Precipitates

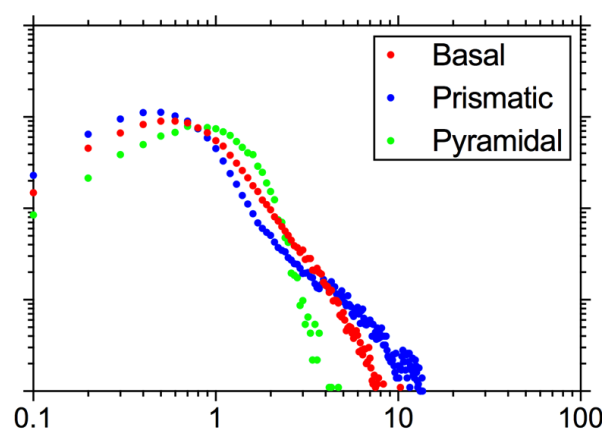

(d)

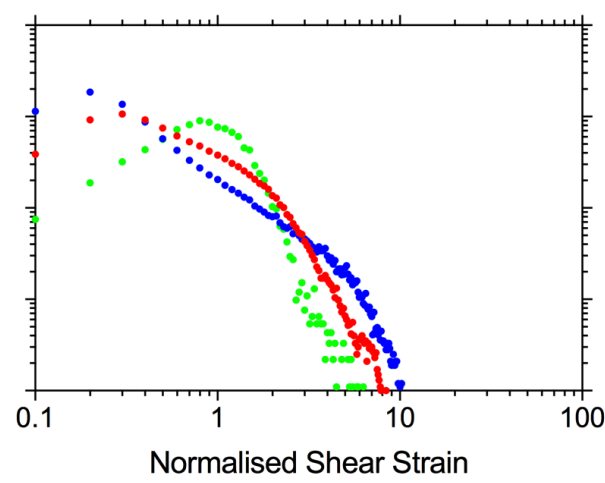

Figure 11- Log frequency distributions of the maximum/average shear strain ratio in each grain for basal, prismatic and pyramidal slip at $1 \%$ applied strain for (a) no $\alpha_{2}$ precipitates and (b) $\alpha_{2}$ precipitates and at 5\% applied strain for (c) no $\alpha_{2}$ precipitates and (d) $\alpha_{2}$ precipitates 
Table 1- Gradients of the log frequency distributions for the no precipitates and precipitates samples in terms of the bulk material, and grains that have deformed by basal, prismatic and pyramidal slip

\begin{tabular}{|l|l|l|l|}
\hline Sample & \multicolumn{1}{|l|}{$\begin{array}{l}\text { Slip Sys- } \\
\text { tem }\end{array}$} & $\begin{array}{l}\text { Gradient of the log frequency } \\
\text { distributions }\end{array}$ \\
\cline { 3 - 4 } & & $1 \%$ & $5 \%$ \\
\hline No $\alpha_{2}$ precipitates & Basal & $-3.87 \pm 0.14$ & $-2.52 \pm 0.17$ \\
\cline { 2 - 4 } & Prismatic & $-2.65 \pm 0.08$ & $-2.57 \pm 0.08$ \\
& Pyramidal & $-3.96 \pm 0.49$ & $-2.87 \pm 0.22$ \\
\hline \multirow{3}{*}{$\boldsymbol{\alpha}_{2}$ Precipitates } & Basal & $-3.22 \pm 0.11$ & $-3.60 \pm 0.10$ \\
& & & $-2.24 \pm 0.14$ \\
\cline { 2 - 4 } & Prismatic & $-1.68 \pm 0.10$ & $-3.85 \pm 0.60$ \\
\cline { 2 - 4 } & Pyramidal & $-7.76 \pm 1.06$ & \\
\hline
\end{tabular}

\section{Conclusions}

By utilising the nanoscale spatial resolution of the high resolution DIC technique we were able to quantify the known increase in strain localisation due to $\alpha_{2}$ precipitation compared to an $\alpha_{2}$-free sample. The experiments on the different material conditions indicate that the level of deformation at $1 \%$ applied strain is more homogeneous in the $\alpha_{2}$-free sample compared to the one that contains $\alpha_{2}$ precipitates. The maximum to average shear strain ratio in the $\alpha_{2}$ containing condition was approximately 20 compared to 11-12 in the $\alpha_{2}$-free material, showing a significant difference in the relative heterogeneity between the two conditions. This was related to the increased slip planarity associated with $\alpha_{2}$. At higher applied strain the strain patterns became more comparable for the two conditions.

Slip trace analysis based on HR-DIC is a technique that was used to identify the primary slip system for each grain. This allowed the plastic deformation behaviour to be directly correlated with prismatic, basal and pyramidal slip, respectively. Significantly, the shear strain contribution relative to the active slip system indicated that for the sample $\alpha_{2}$ precipitation, at low plastic deformation, grains that had deformed by prismatic slip exhibited the most heterogeneous strain behaviour with maximum normalised shear strain values of 15 compared to 8 in grains that had deformed by basal slip. This level of strain heterogeneity for prismatic slip was not evident in the sample without $\alpha_{2}$ precipitates. Furthermore, the high degrees of localised deformation in the grains that had deformed by prismatic slip remained higher at increased applied strains for the $\alpha_{2}$ containing sample. This was not the case for the $\alpha_{2}$-free sample.

Finally, calculating the gradient of the linear portion of the nanoscale frequency distributions was shown to give a quantitative way of characterising and thus comparing the level of strain heterogeneity between the $\alpha_{2}$ and non- $\alpha_{2}$ containing samples and could subsequently be used to compare the deformation behaviour across materials with different microstructural properties.

\section{Acknowledgements}

David Lunt, $\mathrm{Xu} \mathrm{Xu}$ and Michael Preuss would like to thank the EPSRC for financial support through the HEXMAT (Heterogeneous Mechanics in Hexagonal Alloys across Length and Time Scales) programme grant [EP/K034332/1] and material provision by Rolls-Royce plc. Michael Preuss is also particularly grateful for his EPSRC Leadership Fellowship grant [EP/I005420/1].

\section{References}

[1] M. Legros, A. Couret, and D. Caillard, "Prismatic and basal slip in Ti,Al I. Frictional forces on dislocations," Philos. Mag. $A$, vol. 73 , no. 1 , pp. $61-80,1996$.

[2] P. Steele, "IATA Technology Roadmap 2013," 2013.

[3] R. R. Boyer, "Attributes, Characteristics, and Applications of Titanium and Its Alloys," JOM, vol. 62, no. 5, pp. 35-43, 2010.

[4] R. Boyer, "An overview on the use of titanium in the aerospace industry," Mater. Sci. Eng. A, vol. 213, no. 1-2, pp. 103-114, Aug. 1996.

[5] G. Welsch, G. Lütjering, K. Gazioglu, and W. Bunk, "Deformation characteristics of age hardened Ti-6Al-4V," Metall. Trans. A, vol. 8, no. 1, pp. 169-177, 1977.

[6] G. Lutjering and S. Weissmann, "Mechanical Properties of Age-Hardened Titanium-Aluminium Alloys," Acta Metall., vol. 18, pp. 785-795, 1970.

[7] M. J. Blackburn and J. C. Williams, "Stength, Deformation Modes and Fracture in Ti-Al Alloys," Trans. AMS, vol. 62, pp. 398-409, 1969.

[8] F. A. Crossley, "Titanium-Rich End of the Titanium-Aluminum Equilibrium Diagram," Trans. AIME, vol. 236, pp. 1174-1184, 1966.

[9] A. Radecka, P. A. J. Bagot, T. L. Martin, J. Coakley, and V. A. Vorontsov, "The formation of ordered clusters in Ti-7Al and Ti-6Al-4V : a combined TEM and atom probe tomography study," vol. 6141.

[10] T. K. . Namboodhiri, C. . McMahon JR, and H. Herman, "Decomposition of the alpha phase in titanium-rich Ti-Al alloys," Metall. Trans., vol. 4, no. 5, pp. 1323-1331, 1973.

[11] M. J. Blackburn, "The ordering transformation in titaniumaluminum alloys containing up to 25 at. pct aluminum (Ti-Al alloys ordering transformation studied by electron microscopy and electron and X-ray diffraction, showing existence of three 
phase fields)," AIME Transcations, no. 239, pp. 1200-1208, 1967.

[12] N. Singh and V. Singh, "Low cycle fatigue behavior of Ti alloy IMI 834 at room temperature," Mater. Sci. Eng. A, vol. 325, pp. 324-332, 2002.

[13] A. Gysler and S. Weissmann, "Effect of order in Ti3Al particles and of temperature on the deformation behavior of age-hardened Ti-Al alloys," Mater. Sci. Eng., vol. 27, no. 2, pp. 181-193, 1977 .

[14] K. Srinadh, N. Singh, and V. Singh, "Role of Ti3Al / silicides on tensile properties of Timetal 834 at various temperatures," Bull. Mater. Sci., vol. 30, no. 6, pp. 595-600, 2007.

[15] G. Welsch and W. Bunk, "Deformation modes of the $\alpha$-phase of Ti-6Al-4V as a function of oxygen concentration and aging temperature," Metallurgical Transactions A, vol. 13, no. 5. pp. 889-899, 1982.

[16] G. Lutjering, A. Gysler, and L. Wagner, "Crack Propagation in Ti-Alloys," in Sixth World Conference on Titanium, 1988, pp. 71-80.

[17] B. F. Brown, "Stress-Corrosion Cracking in High Strength Steels and in Titanium and Aluminum Allloys," Washington D.C., 1972 .

[18] H. Portish and H. Margolin, "Final Report on Contract No. DAARO(D)-31-124-G519,” Durham, 2000.

[19] S. Zaefferer, "A study of active deformation systems in titanium alloys : dependence on alloy composition and correlation with deformation texture," vol. 344, no. 2003, pp. 20-30, 2002.

[20] Y. Minonishi, S. Morozumi, and H. Yoshinaga, “ $\{1122\}$ $<1123>$ Slip in Titanium," Scr. Metall., vol. 16, no. 4, pp. 427 430, 1982.

[21] G. Lutjering and J. C. Williams, Titanium, 2nd Editio. 2003.

[22] I. P. Jones and W. B. Hutchinson, "Stress-state dependence of slip in Ti-6Al-4V and other HCP metals," Acta Metall., vol. 29 no. 1, pp. 951-968, 1981.

[23] G. Terlinde and G. Luetjering, "Influence of Grain Size and Age-Hardening on Dislocation Pile-Ups and Tensile Fracture for a Ti-AI Alloy," Metall. Trans. A, vol. 13, no. 7, pp. 1283$1292,1982$.

[24] H. Li, D. E. Mason, T. R. Bieler, C. J. Boehlert, and M. A Crimp, "Methodology for estimating the critical resolved shear stress ratios of $\alpha$-phase Ti using EBSD-based trace analysis," Acta Mater., vol. 61, no. 20, pp. 7555-7567, Dec. 2013.

[25] F. Bridier, P. Villechaise, and J. Mendez, "Analysis of the different slip systems activated by tension in a alpha+beta titanium alloy in relation with local crystallographic orientation," Acta Materialia, vol. 53, no. 3. pp. 555-567, Feb2005

[26] J. Quinta Da Fonseca, P. M. Mummery, and P. J. Withers, "Full-field strain mapping by optical correlation of micrographs," J. Microsc., vol. 218, no. April, pp. 9-21, 2005.

[27] F. Gioacchino and J. Quinta da Fonseca, "Plastic Strain Mapping with Sub-micron Resolution Using Digital Image Correlation," Exp. Mech., Oct. 2012.

[28] P. D. Littlewood and A. J. Wilkinson, "Local deformation patterns in Ti-6Al-4V under tensile, fatigue and dwell fatigue loading," Int. J. Fatigue, vol. 43, pp. 111-119, Oct. 2012.

[29] M. A. Sutton, N. Li, D. Garcia, N. Cornille, J. J. Orteu, S. R. McNeill, H. W. Schreier, X. Li, and a. P. Reynolds, "Scanning electron microscopy for quantitative small and large deformation measurements Part II: Experimental validation for magnifications from 200 to 10,000," Exp. Mech., vol. 47, no. 6, pp. 789-804, 2007.

[30] Y. Luo, J. Ruff, R. Ray, Y. Gu, H. J. Ploehn, and W. a. Scrivens, "Vapor-Assisted Remodeling of Thin Gold Films," Chem. Mater., vol. 17, no. 20, pp. 5014-5023, Oct. 2005.

[31] W. A. Scrivens, Y. Luo, M. A. Sutton, S. A. Collette, M. L. Myrick, P. Miney, P. E. Colavita, A. P. Reynolds, and X. Li, "Development of Patterns for Digital Image Correlation Measurements at Reduced Length Scales," Exp. Mech., vol. 47, no. 1, pp. 63-77, Feb. 2006.

[32] D. Lunt, J. Quinta da Fonseca, B. Wynne, D. Rugg, and M. Preuss, "Slip band characterisation in Ti-6Al-4V with varying degrees of macrozones," Proc. 13th World Conf. Titan., pp. 1129-1134, 2016.

[33] F. Di Gioacchino and J. Quinta Da Fonseca, “An experimental study of the polycrystalline plasticity of austenitic stainless steel," Int. J. Plast., vol. 74, pp. 92-109, 2015.

[34] M. Brandes, "Creep, fatigue and deformation of $\alpha$ and $\alpha-\beta$ ti- 4 tanium alloys at ambient temperature," The Ohio State University, 2008.

[35] "http://www.oxford-instruments. com/Pages/home.aspx.” HKL Channel 5, Oxford Instruments.

[36] H. Jin, W.-Y. Lu, and J. Korellis, "Micro-scale deformation measurement using the digital image correlation technique and scanning electron microscope imaging," J. Strain Anal. Eng. Des., vol. 43, no. 8, pp. 719-728, 2008.

[37] “www.lavision.de/en/company.php.” La Vision, Germany.

[38] M. Preuss, J. Q. da Fonseca, V. Allen, D. G. L. Prakash, and M. R. Daymond, "Twinning in structural material with a hexagonal close-packed crystal structure," J. Strain Anal. Eng. Des., vol. 45 , no. 5, pp. 377-390, 2010.

[39] J. C. Williams, R. G. Baggerly, and N. E. Paton, "Deformation Behavior of HCP Ti-Al Alloy Single Crystals," no. March, pp. $837-850,2002$

[40] ASTM E562-01, "Standard Test Method for Determining Volume Fraction by Systematic Manual Point Count," ASTM International, West Conshohocken, PA, www.astm.org, 2001.

[41] D. Lunt, "The effect of macrozones in Ti-6Al-4V on the strain localisation behaviour," University of Manchester, 2014.

[42] M. F. Ashby, "The deformation of plastically nonhomogeneous materials," Philos. Mag., vol. 21, no. 170, pp. 399-424, Feb. 1970.

[43] H. Li, C. J. Boehlert, T. R. Bieler, and M. A. Crimp, "Examination of the distribution of the tensile deformation systems in tension and tension-creep of Ti-6Al-4V (wt.\%) at 296 K and 728 K," Philos. Mag., vol. 95, no. February 2015, pp. 691-729, 2015

[44] H. Li, D. E. Mason, Y. Yang, T. R. Bieler, M. a. Crimp, and C. J. Boehlert, "Comparison of the deformation behaviour of commercially pure titanium and $\mathrm{Ti}-5 \mathrm{Al}-2.5 \mathrm{Sn}(\mathrm{wt} . \%)$ at 296 and 728 K," Philos. Mag., vol. 93, no. 21, pp. 2875-2895, Jul. 2013.

[45] H. Li, C. J. Boehlert, T. R. Bieler, and M. A. Crimp, “Analysis of slip activity and heterogeneous deformation in tension and tension-creep of $\mathrm{Ti}-5 \mathrm{Al}-2.5 \mathrm{Sn}(\mathrm{wt} \%)$ using in-situ SEM experiments," no. September 2012, pp. 37-41.

[46] A. Fitzner, D. G. L. Prakash, J. Quinta da Fonseca, M. Thomas, S.-Y. Zhang, J. Kelleher, P. Manuel, and M. Preuss, "The effect of aluminium on twinning in binary alpha-titanium," Acta Mater., vol. 103, pp. 341-351, Jan. 2016. 